\title{
Tamponade in the surgical management of retinal detachment
}

Kamyar Vaziri

Stephen G Schwartz

Krishna S Kishor

Harry W Flynn Jr

Department of Ophthalmology, Bascom Palmer Eye Institute, University of Miami Miller School of Medicine, Miami, FL, USA
Correspondence: Stephen G Schwartz Department of Ophthalmology, Bascom Palmer Eye Institute, University of Miami Miller School of Medicine, 3880 Tamiami Trail North, Naples, FL 34103, USA

$\mathrm{Tel}+\mathrm{I} 2396593937$

Fax + I 2396593984

Emailsschwartz2@med.miami.edu
This article was published in the following Dove Press journal:

Clinical Ophthalmology

16 March 2016

Number of times this article has been viewed
Abstract: Despite treatment advances, rhegmatogenous retinal detachment (RD) can have poor visual outcomes even with prompt and appropriate therapy. Pars plana vitrectomy is a leading management modality for the treatment of RD. This procedure is generally accompanied by the use of internal tamponade. Various gases and silicone oils may yield beneficial outcomes. Heavy silicone oils have been approved in some European nations but are not available in the USA. Different tamponade agents have unique benefits and risks, and choice of the agent should be individualized according to the characteristics of the patient and $\mathrm{RD}$, as well as perioperative and postoperative factors.

Keywords: tamponade, retinal detachment, silicone oil, gas, air, perfluorocarbon liquids

\section{Introduction}

Despite continuing advances in vitreoretinal care, rhegmatogenous retinal detachment (RD) remains a major cause of visual loss worldwide. There is geographic variation in the incidence of RD, with reported rates ranging from 6.3 to 17.9 per 100,000 population, with a rate of $\sim 12$ per 100,000 in the USA. ${ }^{1}$

The most commonly used treatment modalities for the management of RD are scleral buckling, pars plana vitrectomy (PPV), pneumatic retinopexy, and combination techniques. ${ }^{2}$ Overall, these treatment options have been reported to yield a single operation success rate of $>90 \%{ }^{3}$

In recent years, there has been a trend toward PPV as the preferred method of treatment for RD. In the American Society of Retina Specialists (ASRS) 2014 Global Trends in Retina survey, $78 \%$ of the US respondents preferred PPV, while only 13\% preferred scleral buckling to treat pseudophakic RD without proliferative vitreoretinopathy (PVR). These percentages were $48 \%$ and $23 \%$, respectively, for phakic RD without PVR. ${ }^{4}$

When PPV is chosen for the treatment of RD, it is typically accompanied by the use of a postoperative intraocular tamponade agent.

\section{Intraocular tamponade for retinal detachment Purpose of intraocular tamponade}

"Tamponade" is defined as the use of a tampon, which itself is defined as "a plug or tent inserted tightly into a wound, orifice, etc, to arrest hemorrhage". ${ }^{5}$ In the context of RD surgery, tamponade agents are used to provide surface tension across retinal breaks, which prevents further fluid flow into the subretinal space until the retinopexy (photocoagulation or cryopexy) provides a permanent seal. ${ }^{6}$ Although surgeons may sometimes describe this process to patients as "pushing the retina back into position", this is not generally true. Gases and silicone oils are the most commonly used classes of tamponade agents. 


\section{History of tamponade in retinal detachment surgery}

The first description of the use of tamponade agents in the treatment of RD was given by Ohm in 1911, who reported successful treatment of two patients using intravitreal injection of sterile air, although he did not use the term "tamponade". 7 Later, Gonin described the critical role of retinal breaks in the pathogenesis of RD. ${ }^{8}$ Rosengren, in 1938, reported successful treatment of RD with air, and also used the term "tamponade". 9 In 1962, Cibis et al reported the use of "liquid silicone" in the management of RD, but they also did not use the word "tamponade". ${ }^{10}$

The inert expansile gas sulfur hexafluoride $\left(\mathrm{SF}_{6}\right)$ had been used in the management of pulmonary tuberculosis and pneumothorax because it lasted longer than air. In the early 1970 s, Norton reported the use of $\mathrm{SF}_{6}$ as a vitreous substitute. ${ }^{11}$

In the 1980s, pneumatic retinopexy was independently introduced by Dominguez in Spain and by Hilton and Grizzard in the USA. ${ }^{12,13}$

\section{Properties and characteristics of commonly used agents}

The most common gas tamponades used in the USA are air, $\mathrm{SF}_{6}$, and perfluoropropane $\left(\mathrm{C}_{3} \mathrm{~F}_{8}\right)$ (Figure 1). ${ }^{14}$ In some centers, perfluoroethane $\left(\mathrm{C}_{2} \mathrm{~F}_{6}\right)$ is used. Air is nonexpansile, while $100 \% \mathrm{SF}_{6}$ expands approximately two times over 1-2 days, $100 \% \mathrm{C}_{2} \mathrm{~F}_{6}$ expands approximately three times over 1-2 days, and $100 \% \mathrm{C}_{3} \mathrm{~F}_{8}$ expands approximately four times over 3-4 days. ${ }^{15}$

Small volumes of undiluted gas are typically used for pneumatic retinopexy, but larger volumes of diluted gas are

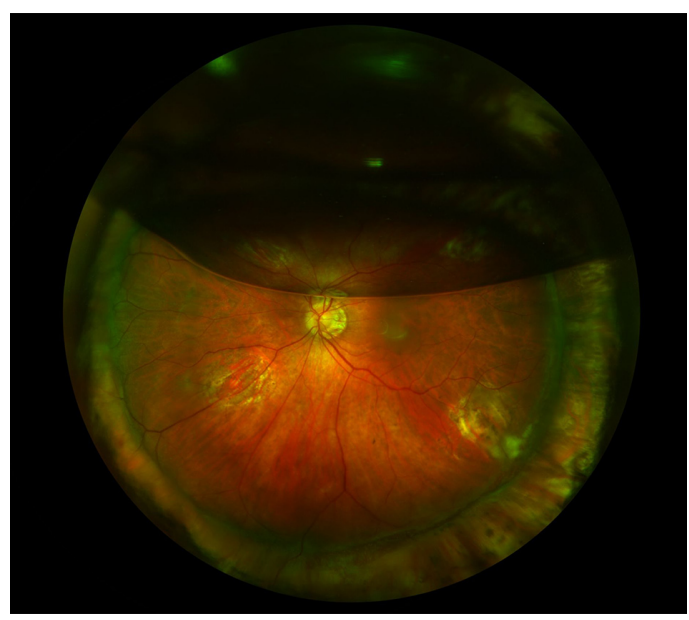

Figure I Fundus photograph of left eye.

Note: Demonstrating a partial gas fill following surgery for retinal detachment. generally used for PPV. Commonly used concentrations are $20 \%$ for $\mathrm{SF}_{6}, 16 \%$ for $\mathrm{C}_{2} \mathrm{~F}_{6}$, and $14 \%$ for $\mathrm{C}_{3} \mathrm{~F}_{8} \cdot{ }^{16}$ Following a complete gas-fluid exchange, gas tamponade agents resorb spontaneously from the vitreous cavity, over a period of 5-7 days for air, $\sim 2$ weeks for $20 \% \mathrm{SF}_{6}, \sim 4-5$ weeks for $16 \% \mathrm{C}_{2} \mathrm{~F}_{6}$, and $\sim 8$ weeks for $14 \% \mathrm{C}_{3} \mathrm{~F}_{8}$.

Unlike gases, silicone oils are permanent and remain in the eye until surgically removed. ${ }^{16}$ Gases have both higher surface tension and higher buoyancy than silicone oils; ${ }^{17}$ therefore, the reported tension exerted by a gas bubble is $\sim 30$ times greater than that of silicone oil. ${ }^{18}$

In the USA, commonly used viscosities of silicone oils include 1,000 and 5,000 centistokes $(\mathrm{cSt}) .{ }^{19}$ Silicone oils have a lower specific gravity $(0.97 \mathrm{~g} / \mathrm{mL})$ than vitreous $(1.005-1.008 \mathrm{~g} / \mathrm{mL}),{ }^{20}$ and as a result, they float in the vitreous cavity. Similarly, gases also float in the vitreous cavity due to their very low specific gravities $(0.001 \mathrm{~g} / \mathrm{mL})$ and they have a much greater buoyancy (upward force) than silicone oils. ${ }^{21}$

Therefore, silicone oils and gases provide less effective tamponade for cases with inferior retinal breaks, which has led to the investigation of heavier-than-water tamponades, including heavy silicone oils (HSOs) and perfluorocarbon liquids (Table 1). ${ }^{15}$

\section{Effectiveness of various intraocular tamponades}

\section{Silicone oil vs gas tamponade}

The Silicone Study ${ }^{22,23}$ was a prospective multicenter randomized clinical trial (RCT) comparing 1,000 cSt silicone oil to $20 \% \mathrm{SF}_{6}$ or $14 \% \mathrm{C}_{3} \mathrm{~F}_{8}$ in patients with $\mathrm{RD}$ associated with PVR. The Silicone Study reported significantly better anatomic and visual outcomes with silicone oil versus $\mathrm{SF}_{6}$ at 1 year, but no significant differences in anatomic or visual outcomes between silicone oil and $\mathrm{C}_{3} \mathrm{~F}_{8}{ }^{21}$

A long-term follow-up report on this study reported that, among the original participants who still had macular attachment at 36 months, there were no significant anatomic or visual outcome differences among silicone oil, $\mathrm{SF}_{6}$, and $\mathrm{C}_{3} \mathrm{~F}_{8}$ groups after follow-up of up to 6 years. ${ }^{24,25}$

The European Vitreo-Retinal Society (EVRS) Retinal Detachment Study was a retrospective study comparing the treatment outcomes of complex RD associated with PVR, giant retinal tear, choroidal detachment, or macular hole. A subanalysis of its first report compared the PPV level-1 failure rates, defined as failed reattachment deemed inoperable by the end of the study, between gas and silicone 
Table I Various tamponade agents used in the treatment of retinal detachment

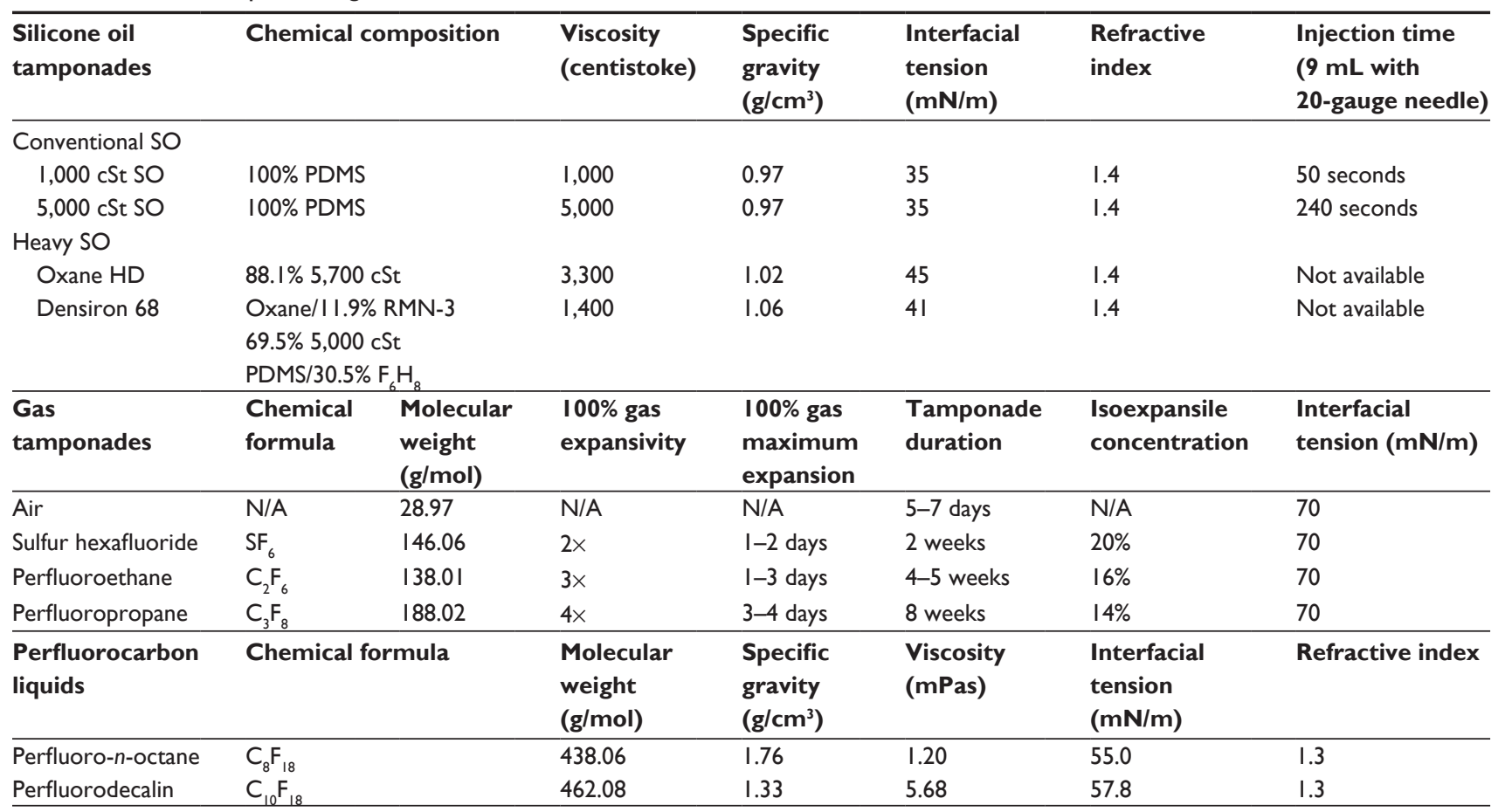

Abbreviations: N/A, not applicable; SO, silicone oil; RMN-3, a partially fluorinated olefin; PDMS, polydimethylsiloxane.

oil tamponade among patients with PVR, and reported no significant differences. ${ }^{26}$

Other smaller studies, however, demonstrated a benefit of silicone oil over gas or vice versa for certain groups of patients. In a retrospective study comparing silicone oil versus $\mathrm{C}_{3} \mathrm{~F}_{8}$ in the treatment of $\mathrm{RD}$ among highly myopic eyes (mean refractive error of $-15.40 \mathrm{D}$ ) with posterior staphyloma, it was reported that $\mathrm{C}_{3} \mathrm{~F}_{8}$ was associated with significantly better initial success rates and significantly better visual outcomes. ${ }^{27}$

In a retrospective series of 56 eyes with recurrent RD associated with PVR and treated with PPV and retinectomy, silicone oil tamponade yielded significantly higher success rates than did gas. ${ }^{28}$ In this study, $88 \%$ of eyes underwent scleral buckle placement or revision during retinectomy, but scleral buckling did not significantly affect anatomic success rates.

In a retrospective study of 97 eyes with rhegmatogenous RD, the Pan-American Collaborative Retina Study (PACORES) group reported that among phakic and nonphakic eyes, the rates of recurrent $\mathrm{RD}$ were similar in both the $\mathrm{C}_{3} \mathrm{~F}_{8}$ and $1,000 \mathrm{cSt}$ silicone oil groups $(P>0.05)$. Further results showed that among patients receiving $\mathrm{C}_{3} \mathrm{~F}_{8}$, recurrent $\mathrm{RD}$ occurred significantly less frequently among nonphakic eyes compared with phakic eyes $(4.5 \%$ vs $28.6 \%$; $P=0.01)$. The same trend was also seen within the silicone oil group but it did not reach statistical significance $(P=0.20) .{ }^{29}$

\section{Air vs other gas tamponades}

Two recent studies have evaluated the efficacy of air vs longer-acting gases with conflicting results. In a retrospective study of 524 eyes with primary rhegmatogenous RD, ${ }^{30}$ it was reported that there were no significant differences overall in the success rates of PPV with air or $20 \% \mathrm{SF}_{6}$ tamponade. In a subanalysis, however, among eyes with inferior $\mathrm{RD}$, air was associated with a lower primary success rate than that of gas.

In a prospective, randomized, comparative study of 64 eyes with RD associated with inferior retinal breaks, there were no significant differences between air and $\mathrm{C}_{3} \mathrm{~F}_{8}$ tamponade in terms of primary or overall anatomic success rates. $^{31}$

\section{Conventional silicone oil: 1,000 vs 5,000 cSt}

In a retrospective series of 325 eyes with complex RD (defined as RD associated with cytomegalovirus retinitis, giant retinal tear, proliferative diabetic retinopathy, PVR, or trauma), there were no significant differences in anatomic success rates or visual outcomes between 1,000 and 5,000 cSt silicone oil. ${ }^{32}$

In another retrospective series of 82 eyes with complex $\mathrm{RD}$, however, the use of 5,000 cSt silicone oil was associated with a significantly higher rate of recurrent RD following silicone oil removal. ${ }^{33}$ 


\section{Heavy silicone oil vs conventional silicone oil} tamponade

Due to low density and high floatation force, conventional silicone oils (and gases) are relatively less effective in the treatment of inferior RD. Heavy silicone oils (HSOs) with higher specific gravities have been investigated for this purpose. Two HSOs that are currently available for clinical use in some European nations, but not approved for use in the USA, are Densiron 68 (a mixture of silicone oil and perfluorohexyloctane; Fluoron, Neu-Ulm, Germany) and Oxane HD (a mixture of silicone oil and partially fluorinated olefin, RMN-3; Bausch + Lomb, Toulouse, France).

The HSO Study ${ }^{34}$ was an RCT comparing Densiron 68 with conventional silicone oil (either 1,000 or 5,000 cSt per surgeon preference) among patients with inferior $\mathrm{RD}$ associated with PVR. The interim analysis of this study reported that, at 12 months, there were no significant differences in the anatomic success rates or visual outcomes between HSO tamponade and conventional silicone oil tamponade. At this time, the final HSO Study results have not been published.

Another randomized, prospective, comparative study that compared PPV with Densiron 68 to 1,000 cSt conventional silicone oil among 61 consecutive eyes with primary RD due to inferior breaks also reported no significant anatomic or functional differences between the two groups. ${ }^{35}$

To date, there have been no large RCTs evaluating the efficacy of Oxane HD. In a prospective, comparative study, PPV with Oxane HD tamponade was compared to conventional silicone oil among patients with complex inferior RDs. The investigators reported no significant differences in anatomic or visual outcomes. ${ }^{36}$

In a small, prospective, RCT involving 20 consecutive patients, PPV with conventional 1,300 cSt silicone oil combined with scleral buckling was compared to PPV with Oxane HD alone in patients with inferior RD associated with PVR. Following silicone oil removal, there were no significant differences in outcomes. ${ }^{37} \mathrm{~A}$ recent systematic review of conventional silicone oil versus $\mathrm{HSO}$ in the treatment of RD reported a trend toward higher rates of ocular hypertension in eyes treated with $\mathrm{HSO}(P=0.02$ in a fixed effect model and $P=0.06$ in a random effect model). ${ }^{38}$

\section{Perfluorocarbon liquids}

Perfluorocarbon liquids are a group of heavier-than-water liquids that are used intraoperatively to reattach the retina, and they are typically removed by the end of the surgery. ${ }^{39}$ These liquids are considered biologically inert but some evidence exists that they may be toxic when retained in the eye for longer periods of time.$^{40}$ Despite these toxicity concerns, some studies have reported beneficial results using perfluorocarbon liquids as short- to medium-term tamponade agents in patients with inferior or complex RD.

In a retrospective series of 62 eyes with giant retinal tear, temporary use of perfluorocarbon liquids (mean of 7.5 days, then exchanged for gas or silicone oil) resulted in a final success rate of $93.5 \%$ with no serious complications reported. ${ }^{41}$

In another retrospective study of 39 eyes with $\mathrm{RD}$ with giant retinal tear or multiple breaks in more than one retinal quadrant, perflurocarbon liquids were retained for a median of 11 days and exchanged for gas or silicone oil. ${ }^{42}$ The authors reported a $100 \%$ reattachment rate.

\section{Complications of silicone oil or gas tamponade}

The use of silicone oil and gas tamponade is associated with several important complications. The Silicone Study reported that chronic postoperative elevated intraocular pressure (IOP) and hypotony occurred in both the $\mathrm{C}_{3} \mathrm{~F}_{8}$ gas and silicone oil groups, with elevated IOP significantly more common with silicone oil and hypotony significantly more common with gas. ${ }^{43}$

Another Silicone Study report evaluated the corneal complications (including corneal edema, corneal opacity, or need for corneal transplant) of silicone oil and gas tamponade. At 24 months, the overall rates of corneal abnormalities were not significantly different between the silicone oil and gas tamponade groups. ${ }^{44}$

Cataract formation is also another common complication associated with both gas and silicone oil tamponade, with reported rates of up to $100 \% .{ }^{45}$ Venous air embolization secondary to fluid-air exchange during vitrectomy has been simulated in donor eyes ${ }^{46}$ following three separately published cases (one fatal) reporting this phenomenon. ${ }^{47}$ Complications unique to silicone oil tamponade include RD associated with silicone oil removal, silicone oil microemulsification, and subconjunctival or suprachoroidal silicone oil. ${ }^{48-50}$

In some cases, the use or removal of silicone oil is associated with unexplained visual loss. One series reported seven such patients who lost three or more lines of Snellen visual acuity associated with the loss of foveal depression on optical coherence tomography. ${ }^{51}$ Another series of 188 eyes reported rates of unexplained visual loss (greater than two Snellen lines) after successful surgery for macula-on rhegmatogenous RD in $0.7 \%$ of eyes treated with gas and $29.7 \%$ of 
eyes treated with silicone oil $(P=0.001)$; the silicone oil-treated eyes demonstrated a small scotoma using microperimetry. ${ }^{52}$ Another series of 421 consecutive eyes treated with silicone oil removal reported a rate of unexplained visual loss of $3.3 \%$ overall, and $50 \%$ in patients with prior macula-on RD associated with giant retinal tear..$^{53}$

\section{Conclusion}

Numerous studies have reported that use of silicone or gas tamponade in the management of RD is generally associated with very favorable outcomes. Among gas tamponades, the Silicone Study demonstrated that both $\mathrm{C}_{3} \mathrm{~F}_{8}$ and silicone oil yielded better outcomes compared to $\mathrm{SF}_{6}$ in eyes with $\mathrm{RD}$ associated with PVR.

While HSOs are approved in certain European nations, they are not available for routine clinical use in the USA. The off-label use of short- to medium-term tamponade with perfluorocarbon liquid has been reported in certain patients with inferior or complex pathology.

The choice of tamponade agent should be individualized based on the location and characteristics of RD, expected patient compliance with postoperative positioning requirements, and other factors. Silicone oil may be preferable in patients unlikely to comply with postoperative positioning (such as children or the mentally impaired), in monocular patients desiring faster visual rehabilitation, or in patients planning air travel shortly after surgery. Using these guidelines, generally favorable outcomes may be obtained for most patients.

\section{Acknowledgments}

This study was partially supported by National Institutes of Health (NIH) Center Core Grant P30EY014801 and an unrestricted grant from Research to Prevent Blindness, New York, NY, USA.

\section{Disclosure}

Dr Schwartz has received consulting fees from Alimera and Bausch + Lomb, speakers' fees from ThromboGenics, and writers' fees from Vindico. All other authors have no financial disclosures and report no conflicts of interest in this work.

\section{References}

1. Mitry D, Charteris DG, Fleck BW, Campbell H, Singh J. The epidemiology of rhegmatogenous retinal detachment: geographical variation and clinical associations. Br J Ophthalmol. 2010;94(6):678-684.

2. Hwang JC. Regional practice patterns for retinal detachment repair in the United States. Am J Ophthalmol. 2012;153(6):1125-1128.

3. Schwartz SG, Mieler W. Management of primary rhegmatogenous retinal detachment. Comp Ophthalmol Update. 2004;5:285-294.
4. Rezaei KA, Stone TW. Global trends in retina. American Society of Retina Specialists. Available from: https://www.asrs.org/content/ documents/2014_global_trends_comprehensivepostmtg.pdf. Accessed September 19, 2015.

5. Tampon, $\mathrm{n}$ [OED online]. Oxford University Press. Available from: http://www.oed.com/view/Entry/197428?rskey=DILTtr\&result=1\#eid. Accessed September 19, 2015.

6. Regillo CD, Tornambe PE. Primary retinal detachment repair. In: Regillo CD, Brown GC, Flynn HW Jr, editors. Vitreoretinal Disease: The Essentials. 1st ed. New York: Thieme; 1998:631-646.

7. Ohm J. Über die Behandlung der Netzhautablösung durch operative Entleerung der subretinalen Flüssigkeit und Einspritzung von Luft in den Glaskörper [On the treatment of retinal detachment by surgical evacuation of subretinal fluid and injection of air into the vitreous]. Albrecht Von Graefes Arch Für Ophthalmol. 1911;79(3):442-450. German.

8. Gonin J. The treatment of detached retina by searing the retinal tears. Arch Ophthalmol. 1930;4(5):621-625.

9. Rosengren B. Results of treatment of detachment of the retina with diathermy and injection of air into the vitreous. Acta Ophthalmol. 1938;16(4):573-579.

10. Cibis PA, Becker B, Okun E, Canaan S. The use of liquid silicone in retinal detachment surgery. Arch Ophthalmol. 1962;68:590-599.

11. Norton EW. Intraocular gas in the management of selected retinal detachments. Trans Am Acad Ophthalmol Otolaryngol. 1973;77(2): OP85-OP98.

12. Dominguez A. Cirugía precoz y ambulatoria del desprendimiento de retina [Early and ambulatory surgery for retinal detachment]. Arch Soc Esp Oftalmol. 1985;48(1):47-54. Spanish.

13. Hilton GF, Grizzard WS. Pneumatic retinopexy. A two-step outpatient operation without conjunctival incision. Ophthalmology. 1986;93(5): 626-641.

14. Mohamed S, Lai TY. Intraocular gas in vitreoretinal surgery. $H K$ J Ophthalmol. 2010;14(1):8-13.

15. Kreissig I, editor. The perfluorocarbon gases. In: Practical Guide to Minimal Surgery for Retinal Detachment. Vol 2, 1sted. Stuttgart: Thieme; 2000: 129-132.

16. Williamson TH, editor. Principles of internal tamponade. In: Vitreoretinal Surgery. 2nd ed. Berlin: Springer; 2013:61-87.

17. Krzystolik MG, D'Amico DJ. Complications of intraocular tamponade: silicone oil versus intraocular gas. Int Ophthalmol Clin. 2000;40(1): 187-200.

18. Petersen J. The physical and surgical aspects of silicone oil in the vitreous cavity. Graefes Arch Clin Exp Ophthalmol. 1987;225(6):452-456.

19. Foster WJ. Vitreous substitutes. Expert Rev Ophthalmol. 2008;3(2): 211-218.

20. Cazabon S, Hillier RJ, Wong D. Heavy silicone oil: a "novel" intraocular tamponade agent. Optom Vis Sci. 2011;88(6):772-775.

21. Lai WW, Yusof W, Lo A, Wong IY, Wong D. Long-term intraocular tamponade with silicone oil. In: Narendran V, Kothar AR, editors. Principles and Practice of Vitreoretinal Surgery. 1st ed. New Delhi: JP Medical Ltd; 2014:145-150.

22. McCuen BW, Azen SP, Stern W, et al. Vitrectomy with silicone oil or perfluoropropane gas in eyes with severe proliferative vitreoretinopathy. Silicone Study Report 3. Retina. 1993;13(4):279-284.

23. Vitrectomy with silicone oil or sulfur hexafluoride gas in eyes with severe proliferative vitreoretinopathy: results of a randomized clinical trial. Silicone Study Report 1. Arch Ophthalmol. 1992;110(6):770-779.

24. Abrams GW, Azen SP, McCuen BW, Flynn HW Jr, Lai MY, Ryan SJ. Vitrectomy with silicone oil or long-acting gas in eyes with severe proliferative vitreoretinopathy: results of additional and long-term follow-up. Silicone Study report 11. Arch Ophthalmol. 1997;115(3): 335-344.

25. Vitrectomy with silicone oil or perfluoropropane gas in eyes with severe proliferative vitreoretinopathy: results of a randomized clinical trial. Silicone Study Report 2. Arch Ophthalmol. 1992;110(6): 780-792. 
26. Adelman RA, Parnes AJ, Sipperley JO, Ducournau D; European VitreoRetinal Society (EVRS) Retinal Detachment Study Group. Strategy for the management of complex retinal detachments: the European vitreo-retinal society retinal detachment study report 2. Ophthalmology. 2013;120(9):1809-1813.

27. Mancino R, Ciuffoletti E, Martucci A, et al. Anatomical and functional results of macular hole retinal detachment surgery in patients with high myopia and posterior staphyloma treated with perfluoropropane gas or silicone oil. Retina. 2013;33(3):586-592.

28. Quiram PA, Gonzales CR, Hu W, et al. Outcomes of vitrectomy with inferior retinectomy in patients with recurrent rhegmatogenous retinal detachments and proliferative vitreoretinopathy. Ophthalmology. 2006;113(11):2041-2047.

29. Caiado RR, Magalhães O, Badaró E, et al. Effect of lens status in the surgical success of 23-gauge primary vitrectomy for the management of rhegmatogenous retinal detachment: the Pan American Collaborative Retina Study (PACORES) group results. Retina. 2015;35(2): 326-333.

30. Tan HS, Oberstein SYL, Mura M, Bijl HM. Air versus gas tamponade in retinal detachment surgery. Br J Ophthalmol. 2013;97(1):80-82.

31. Zhou C, Qiu Q, Zheng Z. Air versus gas tamponade in rhegmatogenous retinal detachment with inferior breaks after 23-gauge pars plana vitrectomy: a prospective, randomized comparative interventional study. Retina. 2015;35(5):886-891.

32. Scott IU, Flynn HW Jr, Murray TG, Smiddy WE, Davis JL, Feuer WJ. Outcomes of complex retinal detachment repair using 1000- vs 5000centistoke silicone oil. Arch Ophthalmol. 2005;123(4):473-478.

33. Soheilian M, Mazareei M, Mohammadpour M, Rahmani B. Comparison of silicon oil removal with various viscosities after complex retinal detachment surgery. BMC Ophthalmol. 2006;6:21.

34. Joussen AM, Rizzo S, Kirchhof B, et al. Heavy silicone oil versus standard silicone oil in as vitreous tamponade in inferior PVR (HSO Study): interim analysis. Acta Ophthalmol. 2011;89(6):e483-e489.

35. Kocak I, Koc H. Comparison of Densiron 68 and $1000 \mathrm{cSt}$ silicone oil in the management of rhegmatogenous retinal detachment with inferior breaks. Int J Ophthalmol. 2013;6(1):81-84.

36. Wickham L, Tranos P, Hiscott P, Charteris D. The use of silicone oil-RMN3 (Oxane HD) as heavier-than-water internal tamponade in complicated inferior retinal detachment surgery. Graefes Arch Clin Exp Ophthalmol. 2010;248(9):1225-1231.

37. Boscia F, Furino C, Recchimurzo N, Besozzi G, Sborgia G, Sborgia C. Oxane HD vs silicone oil and scleral buckle in retinal detachment with proliferative vitreoretinopathy and inferior retinal breaks. Graefes Arch Clin Exp Ophthalmol. 2008;246(7):943-948.

38. Romano V, Cruciani M, Semeraro F, Costagliola C, Romano MR. Development of ocular hypertension secondary to tamponade with light versus heavy silicone oil: a systematic review. Indian J Ophthalmol. 2015;63(3):227-232.
39. Brazitikos PD, Androudi S, D'Amico DJ, et al. Perfluorocarbon liquid utilization in primary vitrectomy repair of retinal detachment with multiple breaks. Retina. 2003;23(5):615-621

40. Georgalas I, Ladas I, Tservakis I, et al. Perfluorocarbon liquids in vitreoretinal surgery: a review of applications and toxicity. Cutan Ocul Toxicol. 2011;30(4):251-262.

41. Sirimaharaj M, Balachandran C, Chan WC, et al. Vitrectomy with short term postoperative tamponade using perfluorocarbon liquid for giant retinal tears. Br J Ophthalmol. 2005;89(9):1176-1179.

42. Rush R, Sheth S, Surka S, Ho I, Gregory-Roberts J. Postoperative perfluoro-N-octane tamponade for primary retinal detachment repair. Retina. 2012;32(6):1114-1120.

43. Barr CC, Lai MY, Lean JS, et al. Postoperative intraocular pressure abnormalities in the Silicone Study: Silicone Study Report 4. Ophthalmology. 1993;100(11):1629-1635.

44. Abrams GW, Azen SP, Barr CC, et al. The incidence of corneal abnormalities in the Silicone Study. Silicone Study Report 7. Arch Ophthalmol. 1995;113(6):764-769.

45. Federman JL, Schubert HD. Complications associated with the use of silicone oil in 150 eyes after retina-vitreous surgery. Ophthalmology. 1988;95(7):870-876.

46. Morris RE, Sapp MR, Oltmanns MH, Kuhn F. Presumed air by vitrectomy embolisation (PAVE) a potentially fatal syndrome. $\mathrm{Br}$ J Ophthalmol. 2014;98(6):765-768.

47. Lim L, Somerville GM, Walker JD. Venous air embolism during air/ fluid exchange: a potentially fatal complication. Arch Ophthalmol. 2010;128(12):1618-1623.

48. Toklu Y, Cakmak HB, Ergun SB, Yorgun MA, Simsek S. Time course of silicone oil emulsification. Retina. 2012;32(10):2039-2044.

49. Asaria RHY, Kon CH, Bunce C, et al. Silicone oil concentrates fibrogenic growth factors in the retro-oil fluid. Br J Ophthalmol. 2004; 88(11):1439-1442.

50. Chang JS, Parke DW 3rd, Flynn HW Jr, Pathengay A, Albini T. Management of suprachoroidal 5,000-centistoke silicone oil: two contrasting approaches. Ophthalmic Surg Lasers Imaging Retina. 2013;44(6):610-612.

51. Williams PD, Fuller CG, Scott IU, Fuller DG, Flynn HW Jr. Vision loss associated with the use and removal of intraocular silicone oil. Clin Ophthalmol. 2008;2(4):955-959.

52. Scheerlinck LM, Schellekens PA, Liem AT, Steijns D, van Leeuwen R. Incidence, risk factors, and clinical characteristics of unexplained visual loss after intraocular silicone oil for macula-on retinal detachment. Retina. Epub 2015 Aug 24

53. Moya R, Chandra A, Banerjee PJ, et al. The incidence of unexplained visual loss following removal of silicone oil. Eye. 2015;29(11):1477-1482.
Clinical Ophthalmology

\section{Publish your work in this journal}

Clinical Ophthalmology is an international, peer-reviewed journal covering all subspecialties within ophthalmology. Key topics include: Optometry; Visual science; Pharmacology and drug therapy in eye diseases; Basic Sciences; Primary and Secondary eye care; Patient Safety and Quality of Care Improvements. This journal is indexed on Submit your manuscript here: http://www.dovepress.com/clinical-ophthalmology-journal

\section{Dovepress}

PubMed Central and CAS, and is the official journal of The Society of Clinical Ophthalmology (SCO). The manuscript management system is completely online and includes a very quick and fair peer-review system, which is all easy to use. Visit http://www.dovepress.com/ testimonials.php to read real quotes from published authors. 